\title{
ANÁLISIS Y PROPUESTA PARA ACTUALIZAR LA MISIÓN PÚBLICA DE TVN
}

\author{
Dr. Valerio Fuenzalida \\ FCOM, Pontificia Universidad Católica de Chile, Santiago, Chile \\ vfuenzal@uc.cl
}

Recibido el 28 de septiembre de 2018

Aceptado el 26 de febrero de 2019

\section{Resumen}

Este texto es un análisis para actualizar la misión social de TVN en tanto estación audiovisual pública al servicio de la ciudadanía chilena. Está escrito con una visión personal de Valerio Fuenzalida quien ha trabajado por 40 años en TV (12 años en TVN), y actualmente es académico de TV en la Facultad de Comunicaciones UC ${ }^{1}$. La propuesta pretende enfatizar algunos temas que se espera sean útiles a quienes toman decisiones para enfrentar una crisis insoslayable.

Palabras clave: Actualización, Misión Pública, Programación, Televisión Nacional de Chile

\begin{abstract}
1 Este texto se ubica en la pragmática de la comunicación televisiva; por ello los datos del contexto políticoindustrial son importantes. Pero, como toda propuesta para la toma de decisiones, ésta involucra opciones con una sustentación técnico-política que se alude brevemente, pero que es imposible reproducir completamente aquí. En un texto breve no es posible abordar en detalle el estatuto jurídico de TVN con sus cambios, ni la evolución de la programación. Aquí se hace una síntesis de puntos sustantivos, en el tema muy amplio de política y toma de decisiones para un canal público de televisión. La mínima bibliografía adjuntada puede ayudar a ampliar la información. La formación del autor es en comunicación y en práctica televisiva, así como en TV pública, información política, y en educación en TV.
\end{abstract}




\title{
ANALYSIS AND PROPOSAL TO UPDATE TVN PUBLIC MISSION
}

\begin{abstract}
This article is an analysis and a proposal to renew the social mission of TV channel Chilean National Television (TVN), as the public TV channel to serve Chilean citizens. It is written from a personal view of the author, who has worked for 40 years in TV ( 12 of them in TVN). He now works as an academic in the school of Communications at the Catholic University in Chile, focused in public TV and TV for Children. The proposal intends to emphasize some subjects for decision making to confront an untenable crisis.
\end{abstract}

Keywords: Revamping, Public Mission, TV Programming, Chilean National Television $(T V N)$

\section{Cómo citar este artículo:}

Fuenzalida, V. (2019). "Actualizar la Misión Pública de TVN", en Perspectivas de la Comunicación, Vol. 12, Nº 1. pp. 315-339. 
Índice

La reforma de TVN en 1992 y los cambios introducidos

Cambios y crisis

I. La Misión de Servicio Público de TVN para Chile.

1. La información plural y balanceada

1.1. Canal segmentado informativo 24 Horas del cable a TV digital abierta

1.2. Diversificar los géneros $y$ formatos televisivos de información

2. Cultura y Educación

3. TVN Regional

4. TV Chile

5. Señal generalista

II. Financiamiento

III. Dirección Superior

En sintesis 


\section{La reforma de TVN en 1992 y los cambios introducidos}

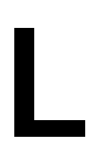

a Reforma de TVN fue aprobada en el Parlamento en el año 1992 luego del uso propagandístico y la pésima gestión económica durante la dictadura; esa reforma debería ser valorada porque le dio a TVN una misión legal de información plural en política, con autonomía del gobierno de turno; y le dio una estructura jurídica y de gestión que apoyara esa misión (ley 19.132 art. $3^{\circ}$; Fuenzalida, 2002). Con el transcurso de la operación de TVN aparecen discusiones y críticas acerca de la misión y la gestión de TVN.

La misión de información política plural involucra tres conceptos que conviene diferenciar: pluralismo, objetividad, y balance informativo. Objetividad es la palabra más controvertida y difícil de operacionalizar. Tal vez la mejor definición que he escuchado es: "objetividad es la conciencia de la subjetividad"; hacerse cargo de la inevitable interpretación personal. La palabra plural alude a representar diversidad; yo personalmente prefiero la expresión información balanceada con presencia de puntos de vista legítimamente diferentes. La información plural y balanceada se operacionalizó en TVN con varias prácticas editoriales.

a) La objetividad en la información se representó con la práctica editorial de la comparecencia personal en pantalla de los diversos representantes políticos de gobierno y de oposición para informar acerca de sus propuestas y contrapropuestas; un periodista no puede sustituir en pantalla la voz informativa de los representantes políticos; las opiniones y posturas, discrepancias o coincidencias deben aparecer audiovisualmente en la voz de la persona representante de quienes las sustentan. Esta práctica representa la objetividad con un principio editorial de representación transparente y responsable de las propias opiniones. El canal TVN y sus periodistas no pueden representar en pantalla las diversas opiniones políticas ni editorializar para apoyar una postura u oponerse a otra ${ }^{2}$.

b) Un parámetro editorial de presencia balanceada en la información ha sido la consonancia con el porcentaje de la representación política en el Parlamento. Tal comparación con datos promedios mensuales de tiempos de pantalla y su relación con los porcentajes del Parlamento ha sido encargada a una agencia externa especializada en medición. Tal balance es criticado por la débil presencia de los grupos minoritarios en una pantalla generalista que tiene tiempo muy limitado, la cual se agudiza con leyes electorales que favorecen la dispersión política en el Parlamento.

c) La práctica editorial de la reunión diaria de pauta del Jefe de Prensa con jefes de las áreas informativas introduce autonomía profesional en la definición de los temas informativos y en su tratamiento. Esta práctica disminuyó sustantivamente la expectativa de algunos políticos de presionar para designar algunos adherentes que supuestamente podrían influenciar la información.

\footnotetext{
2 Esta no es la única manera de representar el pluralismo; en algunos canales europeos se ha optado por la política editorial de hacer visible la diversa postura ideológica de los periodistas y comentaristas de pantalla. La BBC tiene periodistas de gran prestigio y confianza pública en su credibilidad. CNN Chile permite la opinión editorial en algunos temas contingentes de importancia nacional a sus conductores Mónica Rincón y Daniel Matamala; tal práctica es ciertamente evaluada con elogios y rechazos, justamente acerca de la objetividad u "opinología". Todas estas diversas prácticas tienen defensas y oposiciones. Se ha constatado que puede influir mucho más la relación de empatía entre los presentadores con la audiencia que la argumentación racional.
} 
d) La especial conformación plural del Directorio lo constituyó en garante del balance informativo, autónomo del gobierno y con capacidad de decisión dentro de la empresa. Los ejecutivos superiores de TVN, entre ellos el Jefe de Prensa, son propuestos por el Director Ejecutivo al Directorio, y son nominados o destituidos por 4 de 7 votos. La obligación de autofinanciarse buscó cautelar esa autonomía, ya que se presumía que el dinero del gobierno tenía intereses políticos e ideológicos tan fuertes como los de la publicidad, pero la publicidad era una fuente más diversificada que el dinero del Gobierno³.

Esta información plural asignada a TVN como su misión central es un estatuto jurídico y de gestión muy diferente a los canales gubernamentales de América Latina; ellos son agencias de propaganda del gobierno en ejercicio y denigradores de los políticos opositores (en especial en los períodos de dictadura). La gestión del canal depende de un Director designado y destituido por el Ejecutivo; a veces escogido por un Directorio donde el Gobierno designa a la mayoría de los integrantes. Este ejercicio propagandístico en la TV gubernamental se ha continuado hasta fecha reciente en los llamados gobiernos populistas de Kirchner, Maduro, Correa, Morales, Ortega en Centroamérica, y otros (cfr. Caroline Ávila, 2017; Waisbord, 2018). En Chile de forma más o menos soterrada algunos grupos añoran las antiguas políticas de propaganda (el diputado Teillier recientemente -14 de febrero 2017 - pedía "control" del Gobierno sobre TVN para "difundir" las obras del gobierno; afirmaba que esta carencia de control sobre TVN podría conducir al triunfo del candidato opositor Piñera). Todos esos canales latinoamericanos, propagandísticos del gobierno de turno y glorificadores de líderes mesiánicos no tienen credibilidad y por ello tienen una sintonía bajísima; presentan grave deterioro empresarial-industrial, y corrupción en muchos casos.

Después de la dictadura militar han ocurrido cambios importantes en los medios chilenos de prensa escrita, radio, y TV; a) desaparecieron los medios escritos de centroizquierda opositores a la dictadura y se consolidaron los medios escritos que fueron favorables a ese régimen (Sunkel \& Geoffroy, 2001); b) ha ocurrido una importante baja de circulación de la prensa escrita, erosionada por la prensa gratuita y la información digital (Valida-Ipsos); c) en este nuevo escenario cambió sustancialmente la información política en radio y prensa escrita en Chile. Los diarios El Mercurio y La Tercera acentuaron la presencia de comentaristas con puntos de vista políticos diversos, en especial en los cuerpos de fin de semana; lo mismo ocurre en la página editorial donde se presentan opiniones de diversos autores; la sección de cartas del público a menudo se convierte en un importante espacio de debate escrito. En la radio, el cambio de formato evolucionó desde 1970-1973 con un par de destacados comentaristas individuales en dos emisoras distintas (Luis Hernández Parker e Igor Entrala) hacia espacios en post dictadura donde aparecen en la misma emisora dos o tres periodistas y comentaristas que discuten conjuntamente el acontecer político con enfoques diversos.

La información post dictadura ha evolucionado en Chile hacia visibilizar y legitimar la interpretación plural del acontecer político-económico. Ciertamente la necesidad de mayor circulación influye en la presencia de opiniones políticas diversas. Pero, en mi

3 En el hecho, se ha estimado que la renuncia de Jorge Navarrete Martínez, primer director Ejecutivo de la reformada TVN, fue porque el Gobierno del momento habría amenazado con retener las ganancias del ejercicio anual del canal, cuya transferencia al canal fue solicitada para capitalizar a una empresa dejada en bancarrota por la dictadura. 
opinión, en esta evolución ha influido también el standard plural establecido por TVN, que ha logrado una audiencia y credibilidad significativas. El standard plural con audiencia significativa se comprobó viable en Chile y actuó como disuasivo hacia la desinformación: la audiencia rápidamente compara desde su recepción intermedial y desde redes sociales, y advierte la desinformación ${ }^{4}$.

Luego de la Reforma, TVN tuvo unos 15 años muy exitosos (entre 1995-2010) con alta audiencia general, una exitosa área dramática, y con alta audiencia también en sus servicios informativos (que actualmente mantiene en el canal segmentado 24 Horas en VTR cable - el único canal informativo entre los top ten del cable; con mayor sintonía que el canal informativo CNN Chile de la potente empresa global CNN). La ley de Reforma destacó los noticiarios informativos como el núcleo del pluralismo, y TVN por años ha mostrado indicadores de pluralismo balanceado solicitados a empresas externas de medición. En general TVN no ha sufrido una crítica política severa por faltar al pluralismo y ello es reconocido en los diversos partidos. Los indicadores editoriales han sido descalificados por alguna izquierda por su carácter de representación cuantitativa de la presencia parlamentaria, señalando que un pluralismo real de TVN debería bonificar a los grupos políticos emergentes sin representación parlamentaria y con escasos medios de comunicación. También se ha criticado desde la academia la focalización en el género de información noticiosa y la escasa presencia de géneros que favorezcan la deliberación. Más adelante retomaremos estas críticas, sugiriendo mecanismos para mejorar la representación plural y la deliberación social.

\section{Cambios y crisis}

Desde aproximadamente el año 2010, TVN enfrenta un escenario televisivo muy diferente al escenario de la reforma de 1992.

a) Cambios en la propiedad de los canales. La TV abierta chilena se ha privatizado hacia manos de poderosos grupos económicos nacionales, como Mega del grupo Claro y luego Bethia; canal 13 del grupo Luksic; se ha internacionalizado con la presencia del grupo de Ángel González y de la importante red global Turner de Time Warner, que opera CHV y también CNN Chile en cable. Este nuevo escenario obliga a TVN a competir con empresas privadas de una enorme capacidad económico-financiera de respaldo e inversión: la inversión de Mega en la compra de derechos del fútbol (116 millones de dólares hasta el Mundial de 2018), y el desmantelamiento del área dramática de TVN por Mega y TV 13, son ejemplos del impacto de este cambio. Los convenios de colaboración de CHV con CNNTurner, y de Mega con Discovery y la red Globo pueden generar producciones inéditas para la industria chilena.

4 El pluralismo de puntos de vista es, además, concordante con la actual epistemología de la necesidad de diversidad informativa ante la complejidad en la interpretación social, (incluso bajo la influencia del principio de incertidumbre en la ciencia físico-matemática), con la consiguiente desvalorización de los grandes relatos sociales deterministas e infalibles, junto a la información de propaganda. Esta evolución hacia el pluralismo es consonante con la evolución de la información medial en Europa; en Europa durante la primera mitad del siglo XX, algunos países mantuvieron una política pública de fomento a los medios partidarios ("pluralismo externo"), pero el consumo de prensa partidaria en Finlandia bajó del 70\% en 1950 al 15\% en 1995; el "pluralismo interno" ha sido apoyado también por los nuevos estándares éticos en la formación del periodista, donde el servicio informativo panorámico a la ciudadanía es un importante criterio de calidad (Hallin D.C. \& Mancini P., 2004). Ignacio Ramonet, antiguo director de Le Monde Diplomatique, visitó varias veces Argentina en los últimos años, y tuvo contacto con grupos de periodistas. En esas visitas criticó a menudo el "periodismo militante" en favor del Gobierno de turno, en especial en la TV Pública. El periodismo militante no es información, decía. Y defendió el concepto de información de servicio público al servicio de la ciudadanía (10 junio 2014 - Universidad Nacional de Rosario). 
b) La TV de pago ha tenido un espectacular crecimiento en rating conjunto anual (del 6,5\% al 15,2\% entre el año 2008-2016 - Kantar Ibope Media. Cfr. VI Panorama del Audiovisual chileno, Tabla 2, 2 y Gráfico 2,1).

c) Desde el punto de vista del financiamiento publicitario, con excepción de Mega, todos los canales abiertos presentan pérdidas considerables; la publicidad total no ha aumentado pero ha desplazado su inversión hacia Internet y hacia la TV de pago (que tiene un doble financiamiento: por el canon de abono y por la publicidad en pantalla).

d) Ha ocurrido la clásica dispersión de audiencia entre más opciones disponibles para sintonía: como se ha mencionado, el cable ha tenido un amplio crecimiento, además de la atracción en especial de niños y jóvenes por la TV no-lineal en streaming sintonizada en tablets y smartphones. La TV abierta en conjunto ha sido afectada con una caída de audiencia: en el caso de TVN pasó de un primer lugar en el año 2001 con 12,9\% de rating promedio anual a un primer lugar de sintonía con $8,50 \%$ de rating en el año 2006 y a un primer lugar con $7,62 \%$ de rating anual el año 2010. Pero en el año 2016, TVN fue desplazado a un cuarto lugar entre los canales abiertos con $4,20 \%$ de rating anual, sumando a la crisis general de la TV chilena su propia crisis en audiencia y gestión.

e) El cambio tecnológico en el audiovisual no solo afecta a la recepción por diversos dispositivos en diferentes lugares (TV every where every time) sino también a la emisión audiovisual en multiplataforma, que requiere importantes inversiones económicas en equipos 5 .

La actual situación de crisis general en la TV chilena y en particular de TVN obliga a revisar la triada de aspectos decisivos para un canal público: la misión de Servicio Público de TVN, el financiamiento económico, y la dirección superior ${ }^{6}$. Esto significa analizar cuál puede y debe ser la emisión de servicio público de TVN, que se concretiza en una programación con determinados énfasis, hacia cuáles públicos destinatarios (con sus diferentes intereses y preferencias); cómo se financia el costo de producción de esa programación, y de la innovación tecnológica de la infraestructura para producción/emisión; cómo se estructura la dirección superior en una empresa audiovisual pública de modo que su gestión sea satisfactoria para la audiencia y sea eficiente en la asignación de los recursos. La triada de Misión-Programación, Financiamiento, y Dirección se desglosa en múltiples opciones y decisiones. No existe un manual universal con un esquema único a seguir. Revisar las múltiples opciones (actuales, posibles y fracasadas) ocuparía un espacio muy amplio, y sería contradictorio con el propósito pragmático de este texto7. Por ello nos

\footnotetext{
5 Para tener información más detallada acerca de estos cambios ver las seis ediciones del Panorama del Audiovisual chileno. Facultad de Comunicaciones. PUC. 2018.

6 El Gobierno de la Presidenta Bachelet había solicitado al Congreso aprobar una inyección por alrededor de 65 millones dólares a TVN. Solicitud que fue mirada con desconfianza en el Parlamento. Personalmente he sostenido en público que antes de aprobar inyecciones de dinero, hay que evaluar y actualizar la misión de Servicio Público de TVN para determinar si es socialmente valioso hacer una inversión económica, y proponer, si fuese necesario, otros mecanismos de financiamiento que solo el actual únicamente publicitario.

7 A menudo se habla de una TV Pública con programas de calidad. El concepto de calidad en TV tiene diferentes acepciones; Mulgan Geoff en 1990 describía en Gran Bretaña siete distintas formulaciones de calidad. Por tanto, es un concepto muy equívoco y poco operativo. Cfr. ¿Qué es calidad en TV? Valerio Fuenzalida. Segundo Informe Anual Televisión Chile. ANATEL. Santiago Edición 2014, p. 62-64.
} 
concentraremos en proponer soluciones a los problemas de TVN en el contexto social y político chileno.

\section{La Misión de Servicio Público de TVN para Chile.}

\section{La información plural y balanceada}

Esta es la única misión explícitamente asignada a TVN en la reforma del año 1992, y en mi opinión se debe mantener y perfeccionar. Es el momento de retomar las discusiones críticas a este respecto. Yo sostengo que esa misión de información balanceada es necesaria para la gobernabilidad democrática chilena en un país en que la prensa privada está muy concentrada ideológicamente y no tiene el carácter de "watch dog" de la prensa de USA, bastante más independiente. La información (38.8\%) y la ficción (40.6\%) son los contenidos con mayor rating anual en la TV chilena abierta (cfr. Panorama del AudiovisualFCOM). En general TVN ha sido un canal reconocido por cumplir el pluralismo en la información y ha actuado como un influencia pluralizadora de otros medios ${ }^{8}$. Pero hay varios importantes cambios por introducir para ampliar la información.

\subsection{Canal informativo segmentado en TV digital abierta}

Para ampliar la información, es necesario tener un canal segmentado informativo 24 Horas en TV digital abierta para expandir la cobertura de audiencia al acceso a la información, ampliando también el tiempo informativo con el esquema 24/7; ello permite extender la información permanente a más personas, en especial quienes no tienen acceso al canal 24 horas de TVN en cable.

\subsection{Diversificar los géneros y formatos televisivos de información}

La ampliación del tiempo diario de información permite, además, diversificar los géneros y formatos televisivos de información. Los diversos géneros formatean la información con énfasis propios. El género del noticiario, preponderante en la información de los actuales canales generalistas, tiende a enfatizar la discusión política contingente (junto con acontecimientos conmocionantes del acontecer); la información política contingente es representada/formateada en la pantalla como una lucha por parte de líderes del Gobierno con otros de la oposición, frente a cada tema y propuesta. Los problemas de mediano y largo plazo tienden a ser postergados o se les dedica poco tiempo; en el género de noticiario, la contingencia presiona por presencia en pantalla y se impone un formato de lucha de poder para la exhibir la bondad de la propuesta del Gobierno o la crítica a su insuficiencia por la oposición. La inmensa mayoría de la ciudadanía más bien puede mirar el debate de estos pocos actores, con escasas posibilidades de participar.

Más géneros de información en TVN introduce la posibilidad:

a) Programar diariamente el género de debate plural entre más personas con diversos puntos de vista, pues es el género clave que permite ampliar la deliberación sobre los temas de actualidad con más opiniones valiosas y relevar también los postergados problemas de mediano y largo plazo. Este género permite ampliar la presencia no solo de representantes políticos sino también de otros dirigentes sociales, y la representación de movimientos emergentes con miradas innovadoras. Es un género que permite incorporar a más ciudadanos a la discusión social y a la deliberación acerca de diagnósticos y soluciones en

8 Con excepción del Gobierno del Presidente Aylwin, creador de la Reforma, los presidentes posteriores han intentado con diferentes medidas de presión influenciar la información de TVN hacia las posturas oficialistas; esto es muy difícil, pues la línea editorial y los encargados de llevarla a cabo dependen del Directorio de TVN. 
temas importantes: expertos, propuestas de innovación, aprendizaje de la experiencia exitosa y fracasada; permite convocar más energía social y experiencia útil para soluciones ante problemas en la salud, la educación, la inseguridad, la reclusión de delincuentes, inclusión social, drogas, y otros. Un canal segmentado en información 24/7 permite mayor presencia de este género para ampliar la participación y la deliberación ciudadana. $Y$ es posible tener deliberación más profunda en temas segmentados y con participantes diversos. Este género representa la política aludiendo al sentido griego de la deliberación ciudadana en el ágora de Atenas, la cual sin embargo incluía solo al pequeño grupo de los ciudadanos griegos, y excluía a mujeres, sectores populares y esclavos.

Pero, este género tiene limitaciones; muy a menudo no tiene la sintonía deseable pues es considerado difícil de comprender por una audiencia que desea descansar en el hogar y para ello prefiero espectáculos y ficción. Hay evidencia que en muchos casos la audiencia se desorienta con discusiones acerca de puntos de vista que no logra comprender (Soukup, 2014,7 ). Los periodistas conductores tienen, entonces, un rol indispensable para facilitar la comprensión de las audiencias sintetizando los puntos centrales del tema con las coincidencias y los desacuerdos entre los participantes. Los políticos participantes tienen un doble foco de atención (en tensión): a la discusión retórica con los otros panelistas, y a la audiencia para persuadirla acerca de la mejor solución a un problema ciudadano. Nuevamente es muy importante el rol del conductor para vincular la discusión en pantalla con información acerca de las necesidades y preguntas de la audiencia.

Pero aun así sigue siendo un género complejo por su alta abstracción; aparece la necesidad de involucrar emocionalmente a las audiencias en la información (Uribe, 2007). La audiencia se involucra más en temas complejos cuando ellos atañen a la vida cotidiana de las familias, hogares y barrios; y cuando ellos son representados en base a experiencias personalizadas; la ficción y el docudrama aparecen (en casos cuidadosamente trabajados) como géneros capaces de entregar información y reflexión desde el interior de la narración dramática. El cine está poblado de películas basadas en sucesos reales. La telenovela Machos (canal 13 - 2003) en Chile fue capaz de hacer reflexionar masivamente a las familias en el hogar acerca de la exclusión social de un personaje homosexual masculino. El docudrama Mea Culpa (TVN - 1993-2009) planteaba en cada episodio crímenes y delitos de personas reales que habían elaborado su arrepentimiento. Mujer Rompe el Silencio (Mega - 2003-2004) planteaba casos reales ficcionalizados de problemas que afectan a la mujer en su vida cotidiana (Fuenzalida 2008). La investigación de la recepción con la interpretación por las audiencias muestra por una parte que la comparecencia en TV de problemas sociales debe concretizarse en la vida cotidiana de la audiencia (esto es, no abordar los problemas con un lenguaje técnico y abstracto), y por otra parte, que la conciencia y comprensión de las situaciones se hace por la identificación emocional de la audiencia con una ficción que aparece como un espejo personalizado relativamente análogo con la vida. (Fuenzalida, 2005; 2007) La identificación es la experiencia de sí mismo en el otro ficcional, explica Jauss (1982).

b) Otro formato informativo con posibilidad de adquirir más presencia en la pantalla son los programas que abordan temáticas segmentadas de la audiencia. TVN ha creado espacios de diferente longitud en presencia de pantalla ante temas económicos; Exploradores presenta información de Ciencia y Tecnología. El Especialista presenta respuestas de expertos en pantalla ante consultas de la audiencia en temas de salud relacionados con épocas del año. 
c) Otro formato relacionado con programas híbridos de información-entretención es la comparecencia en pantalla de ciudadanía afectada por problemas personales y por malos servicios públicos y privados. Los programas de denuncia de deficientes servicios, públicos y privados, a la ciudadanía son difíciles de comprobar fehacientemente; las investigaciones de comprobación son lentas y costosas; las agencias acusadas no comparecen en conjunto con los denunciadores por un clima potencialmente belicoso e insultante; los canales se exponen a demandas y juicios por afirmaciones sin fundamento. En cambio, se han producido diversos programas para mediar problemas judiciales (y otros) entre familiares y vecinos como el programa La Jueza (CHV; 2007-2017), Veredicto (Mega; 2007-2011), Tribunal Oral (canal 13; 2007). El programa la Jueza se trasladó a TVN (2018) bajo el nombre de Carmen Gloria a tu Servicio. Estos programas se han adaptado a partir del programa Caso Cerrado (2001) de la red en español Telemundo de NBC en USA, exhibido por muchos canales latinoamericanos y chilenos. Estos programas son objeto de desvalorización y burlas en diversos ambientes (clase alta, académicos, políticos); pero ellos existen por la hibridación de los géneros televisivos ${ }^{9}$; y también por la persistente mala calidad de los servicios públicos para la prevención y sanción de diversos conflictos de pareja, familiares y vecinales. Según la ONU, América Latina es la región más violenta contra la mujer con un promedio de 12 asesinatos diarios (ONU Mujeres América Latina y el Caribe, 2017). Es bastante obvio que ese contexto influye en la presencia televisiva y en la sintonía de esos programas, así como en los programas acerca de delincuencia.

La Vega (TVN 2016-2018) es un docurreality que exhibe jóvenes del grupo "ni ni", (que no trabajan ni estudian). Ellos aparecen en un programa de TVN que los hace trabajar en el gran mercado La Vega en Santiago y son remunerados en cantidad ascendente si logran ciertas metas. Sus familias, cansadas del "ni ni", los impulsan a postular a este programa donde aprenden a trabajar, en un formato televisivo de concurso de pruebas por superar para lograr premios y con un tono de humor y alegría.

Los anteriores programas son producciones que han reelaborado el programa Cuéntame (TVN, 1994-1997). En ese programa diario se conversó acerca de todos los temas presentes en la vida social y familiar; era una conversación a tres bandas: testimonios personales de problemas, opiniones de expertos acerca del tema, y agencias sociales de apoyo a esas situaciones. La conversación se iniciaba con la presentación del tema por invitados que contaban su experiencia a través de sus historias personales; esos testimonios eran proferidos por personas corrientes de estratos medios y populares; luego ocurría una profundización con expertos quienes entregaban una perspectiva más informada para comprender las experiencias y orientar hacia soluciones. Finalmente intervenían centros y agencias sociales que pudiesen ayudar a las personas en la solución adecuada de la temática. Cuéntame pretendía expandir la energía socio-afectiva que se manifestaba en variados centros de ayuda, y cuya presentación televisiva era indispensable para fortalecer las redes de acción solidaria. Sin embargo, las evaluaciones del programa entre sus receptores destinatarios, fue mostrando que el programa suscitaba con gran facilidad emociones ingratas que ahuyentaban a un sector importante de televidentes. La presentación y música inicial ya comunicaban un tono poco alegre al programa. La escenografía del programa con colores fríos y con una disposición espacial muy distante

9 La tradicional diferencia entre información, educación y entretención se considera hoy irrelevante y anticuada la entretención se opone al aburrimiento y no a educación o información. Los géneros se hibridan y aparecen la info-entretención y la edu-entretención. El aprendizaje y la memoria están asociados a emociones positivas, según la neurociencia del cerebro. 
entre los participantes era percibido como un espacio físico-sicológico de poca calidez, acogida, e intimidad $y$, por el contrario, deprimía sugiriendo emociones negativas en los televidentes. El tono emocional negativo percibido por la audiencia era tan fuerte que en algunos casos las agencias de apoyo presentes se volvían invisibles para la audiencia. Se decidió trasladar el programa a la tarde, después de la telenovela postmeridiana; allí el programa compitió con otro programa de servicio al Hogar en otro canal, cuya conductora Eli de Caso desbordaba energía también ante temas dolorosos, y se esforzaba por comunicar asertividad a su audiencia para enfrentar sus problemas. De nuevo el contraste fue percibido negativamente para Cuéntame. El programa finalmente fue retirado de pantalla (cfr. Fuenzalida, 2005, cap.3).

Los nuevos programas con información-entretención presentas dos rasgos ausentes de Cuéntame: el centro del programa no son los problemas sino las soluciones, proferidas con asertividad y credibilidad. El tono emocional del programa se traslada a energía, alegría y humor. La neurociencia y el aprendizaje acerca de programas de info-entretenimiento muestran la importancia de las emociones positivas que marcan el conocimiento, memoria, y motivan a buscar información; junto al ritmo televisivo del programa y la conexión con los intereses temáticos de la audiencia.

Estos programas informativos con los nuevos formatos de información-entretención representan a la ciudadanía que puede exhibir la vulneración de sus legítimos derechos y exigir obtenerlos. A los críticos de estos programas se les ha recordado que el aspecto de los derechos demandados alude al sentido introducido por Roma de una ciudadanía con derechos exigibles.

d) El formato de entrevista en pantalla televisiva a un dirigente destacado es muy deseado por los propios dirigentes. Pero la entrevista política individual en TV es un formato con dificultades. En la entrevista individual una retórica hábil conduce la entrevista hacia los temas de interés del propio entrevistado; un periodista demasiado inquisidor puede provocar tensión excesiva y ser acusado de acoso político. Es un formato de lucha entre los intereses de publicidad del entrevistado y los intereses de escrutinio del entrevistador, que se supone representa a la audiencia (lo cual no siempre es así, pues un entrevistado importante escoge al entrevistador). En mi opinión es un formato que debería tener menor presencia de pantalla que el debate con varios participantes.

e) El género de investigación televisiva se exhibe con grandes reportajes y documentales en espacios especiales (Informe Especial - TVN, 1984i Contacto, canal 13, 1991-2016) pero también crecientemente en secciones al interior del Noticiario central de un canal. El caso Karadima, el caso de la estafa de "los quesitos", Paul Schaefer dirigente escondido de Colonia Dignidad, y otros casos, han sido develados por la investigación televisiva. La potencia de este formato se manifiesta en que a menudo la prensa escrita del día posterior lo menciona en sus páginas. Supone recursos y hábiles periodistas de investigación. Es un formato de investigación altamente apreciado por la audiencia y temido por los afectados. También tiene diversas variantes de más o menos cercanas a la info-entretención como Misión Encubierta (Mega - 2017), En su propia Trampa (canal 13, 2011-2017). El periodismo de investigación es un género televisivo de gran importancia para investigar la corrupción y las colusiones contra la ciudadanía. Exige periodistas de mucha experiencia que hayan trabajado en excelentes programas chilenos, y que conocen, además exitosos programas extranjeros. 
Se han mencionado estos diversos géneros y formatos de información (algunos híbridos de info-entretención), los cuales deben enriquecer la oferta informativa de TVN operando un canal segmentado $24 / 7$ en TV digital abierta. Es parte de los cambios necesarios para expandir la cobertura de una información indispensable para la gobernabilidad democrática. Como este abanico de formatos no es presentado por canales que únicamente se preocupan del género de los noticiarios, puede constituirse en una diferencia en la misión informativa de $\operatorname{TVN}^{10}$.

Estos diversos formatos son enseñados de manera deficiente en las escuelas chilenas de periodismo audiovisual, y así los nuevos periodistas no manejan todo el abanico de formatos posibles de información, abanico necesario para ofrecer a la ciudadanía calidad de información ${ }^{11}$.

\section{Cultura y Educación}

La reforma no asignó a TVN sino vaguedades en torno a educación y cultura. $Y$ ha sido mejor así, pues ambos temas son ambiguos y en evolución.

El tema cultural presenta tradicionalmente varios problemas: uno es la aspiración verbalizada de la audiencia junto a la presión académica por exhibir programas culturales, aspiración que no se refleja para nada en la sintonía a estos programas ${ }^{12}$. Otro problema es la definición de cultura; un tercero es la aspiración por un canal cultural segmentado, y un cuarto es la aparición del concepto de industrias culturales.

La definición de cultura fluctúa entre un sentido muy amplio que engloba costumbres cotidianas, antropología y etnografía cultural, folklore, historia de tradiciones, cultura popular; Canal 13c se ubica más bien en esta acepción. Cultura en sentido restrictivo está más circunscrito a Bellas Artes, nacionales e internacionales, exhibición de obras consagradas y conversaciones con destacados intelectuales (Film \& Arts está más cerca de esta acepción). Además de la cultura cotidiana y las Bellas Artes también los canales culturales fluctúan entre presentar obras consagradas y presentar a nuevos creadores. Se advierten estas tensiones en los canales que evolucionan y se hibridan: Films and Arts, el canal cultural con mayor presencia en Chile, exhibe también cultura popular con destacados creadores, y espacios de conversación con artistas de música popular, teatro y cine. El canal ARTV se dedicó en sus últimos años a programar documentales, especialmente obtenidos del canal satelital TAL; pero los documentales eran simplemente pegoteados uno tras otro sin curatoría que los agrupara y los introdujera a la audiencia. El documental es un género difícil para la audiencia; la BBC ha hecho un esfuerzo exitoso en producir documentales de atractivo para la audiencia en su temática y en su realización;

\footnotetext{
10 La necesidad de complementar una TV Pública de calidad informativa con información de calidad provista por la TV privada se hace patente en algunos momentos en que la clase política en conjunto reacciona corporativamente al sentirse agredida y ofendida por la prensa. Una TV pública finalmente dependiendo del Parlamento, está amenazada por muchos poderosos mecanismos para atenuar las críticas a la clase política en conjunto, como ocurre en situaciones de críticas sociales trasversales por los altos salarios y beneficios de los parlamentarios, o el privilegio del fuero que dificulta la investigación de corrupción. En esas situaciones una TV Pública puede ser más vulnerable que estaciones privadas.

11 Lo que en mi opinión no tiene justificación son los canales chilenos del Parlamento con un gasto de alrededor de 5 millones de dólares anuales y con una audiencia insignificante. Ellos no han logrado convencer a la ciudadanía de la importancia de su tarea ni prestigiar a los representantes. Ese dinero entregado a TVN para ser trabajado profesionalmente en información podría revertir la desvalorización del poder legislativo.

12 Habitualmente en las encuestas de opinión aparece la crítica por exceso de telenovelas y la aspiración por presencia de más programas culturales.
} 
pero hay documentales de autor, donde el tema es interesante para el autor y su forma de realización a menudo es experimental.

Los canales culturales internacionales por satélite tienden a exhibir obras consagradas de valor universal; los canales nacionales son presionados a exhibir cultura nacional consagrada de alto costo de producción. Los canales regionales tienen la posibilidad de exhibir más cultura con identidad local, y a creadores emergentes regionales; más adelante se volverá sobre la cultura regional en canales regionales, como los festivales regionales que ya actualmente presenta TVN (Olmué, Talca) grandes eventos de cultura popular y de alta audiencia.

El tema cultural se ha entremezclado con el nuevo aspecto de las industrias culturales, de alto consumo y de creciente importancia económica. La TV y la radio no solo pueden exhibir obras creadas para otras situaciones de recepción (salas de teatro, y de concierto, festivales); también han creado obras audiovisuales propias (telenovelas, series de ficción, series infantiles, reportajes, concursos, y otras), cuya capacidad de circulación internacional es importantísima para la subsistencia económica de estas producciones y de la industria. Los concursos de fondos públicos deberían premiar a los creadores que tienen éxito de audiencia internacional y no solo por su premiación en festivales con un público selecto y minoritario.

El aspecto de la forma de exhibir cultura fluctúa entre franjas obligatorias para los canales generalistas en TV abierta, establecidas en Chile por el CNTV, y la aspiración por un canal cultural segmentado nacional, formulada por el Ministerio de las Culturas. Hay mucha información consistente que la temática cultural tiene una audiencia segmentada con un bajo rating ${ }^{13}$, y con un alto costo de producción. La creación de un canal cultural emisor se facilita hoy día las tecnologías de nicho en streaming, el Video on Demand (VOD), y canales en YouTube. Estas tecnologías de emisión tienen menor costo de instalación, están ampliamente difundidas, y los sectores más jóvenes están muy familiarizados con ellas. En Chile ya existen bastantes lugares con importantes repositorios gratuitos (públicos y en cable) de cine nacional. Hace falta más publicidad para estos múltiples lugares de la Web, publicidad que podría ser asumida de modo constante por el CNTV y el Ministerio de las Culturas. Los canales culturales hoy pueden ser hoy mucho más segmentados con las tecnologías de nicho en streaming, para consumo de los aficionados en diversas artes, y en el aula. Este es un aspecto dinámico que se deberá evaluar con cuidado para no tomar decisiones costosas y en rápida obsolescencia.

\section{Educación y Canales para Niños}

En el aspecto de educación en TV, hay que destacar que desde fines de los '9o se han creado en la mayoría de los países canales segmentados infantiles en TV abierta y de pago; ellos están entre los top ten del cable. Exhiben nuevos programas educativo-entretenidos, inspirados por la neurociencia del cerebro infantil y por otras disciplinas del desarrollo evolutivo del niño; estas ciencias han impulsado un cambio en la concepción educativa de la TV para los niños. Y descubrieron dos características nuevas para una TV infantil de calidad.

13 El caso de radio Beethoven es ilustrativo; luego de la constante crisis económica por la baja publicidad comercial, la emisora se ha integrado a un grupo radial privado, conservando su carácter segmentado. 
Por una parte, las competencias internas genéticas del niño que requieren una conexión epigenética con los estímulos culturales. Las nuevas competencias descubiertas se focalizan en el desarrollo de la inteligencia socio-emocional y en las capacidades ejecutivas de los niños, en el manejo de la energía emocional personal y la comprensión de las emociones de los demás, la autoconfianza, la creatividad, la actividad e iniciativa emprendedora, la toma responsable de decisiones, la "resiliencia" y otras competencias. Estos son aspectos educativos que la escuela descuida por su focalización en lectura y matemáticas, pero que hoy se consideran claves en una educación integral de calidad. Los nuevos programas se producen con nuevos criterios de calidad, como representar lúdicamente a un niño capaz, activo y competente, con interacción desde la pantalla para desafiar las capacidades de la audiencia infantil, niño protagonista hacia metas de logros, estimulación de la inteligencia socio-emocional, representación de competencias de sí mismo, tono emocional de alegría y disfrute del programa.

Por otra parte, la recepción constructivista de los programas por parte de los niños aumenta sustantivamente su comprensión educativa y apropiación actitudinalconductual. La educación actual plantea que el aula escolar en educación parvularia y en el primer ciclo básico es el momento de mayor productividad en la educación, y a ello contribuye la recepción constructivista de esta nueva TV.

Con los canales segmentados infantiles del cable, el modelo de inserciones de franjas infantiles diarias en línea dentro de un canal generalista quedó obsoleto en la última década para la audiencia infantil, porque ella se habituó (con las nuevas tecnologías de emisión) a elegir canales y a seleccionar programas en sus propios horarios y dispositivos. Tecnológicamente hay varias alternativas. Yo he propuesto una señal infantil en TVN para emitir en multiplataforma no-lineal una programación segmentada hacia un público de niños; la experiencia internacional de producir una señal infantil en un canal de TV pública muestra la opción de crear un canal segmentado lineal entre $06.00 \mathrm{am}$ a las $21.00 \mathrm{pm}$ (aproximadamente) y el resto del tiempo para otro canal con otra programación, con una identidad diferente de marca, de contenido y de público (juvenil o cultural). Existe la tecnología MAM (Media Asset Management) que permite tener un repositorio de diferentes programas audiovisuales y ser recibidos por Internet, seleccionando la audiencia los programas que le interesen.

Un canal infantil segmentado y multiplataforma, recibido constructivamente en el aula y en el hogar se ha demostrado eficiente para contribuir a mejorar la calidad de la educación inicial, la etapa más importante en la educación. Dado que la programación se repite cada dos tres años para las nuevas audiencias tiene un costo de financiamiento mucho más bajo que otros canales (Fuenzalida, 2016).

Modernizar TVN creando un canal infantil vinculado al aula propone a la ciudadanía una nueva forma de servicio público a la familia y a los niños, el cual es apreciado y agradecido por los padres ${ }^{14}$.

Mirar como ideal por reproducir a la PBS de Estados Unidos sería repetir un sistema televisivo pobre en contenidos interesantes para la audiencia y por ello con audiencia ínfima ("la TV Pública sin público", como se ironiza en Gran Bretaña), y sin influencia social ni cultural masiva (excepto por su aporte de cooperación en USA a una TV infantil de

14 El autor ha sido consultor para crear un canal público infantil para México, y para la República de El Salvador. 
calidad). Nuevamente la tecnología es muy dinámica y puede volver obsoleto un canal infantil tradicional al ser reemplazado por streaming en la sintonía de la audiencia.

\section{TVN Regional}

Este es un antiguo anhelo de crear canales regionales que aporten a la vida socio-cultural y al desarrollo económico-político regional. Ha sido obstaculizado especialmente por el temor al surgimiento de liderazgos políticos regionales, amenazantes para la dirigencia capitalina. Hoy parece existir un mayor consenso en esta necesidad de contribuir a la visibilidad de los esfuerzos regionales en desarrollo y emprendimiento económico, en proyectos en turismo y en cultura, y en fortalecer una capa dirigente regional. Un canal cultural en Santiago estará fuertemente presionado a exhibir la creación capitalina y dispondrá de muy poco espacio y dinero para creadores regionales. Cada canal regional puede exhibir, en cambio, algunas horas semanales con creación cultural local.

Una reforma seria de TVN debe proponerse la creación de emisoras regionales. Su manejo debe ser integrado a TVN para garantizar la autonomía política.

\section{TV Chile}

La actual señal internacional de TVN debería tener un consejo consultivo para asumir con más claridad algunos rasgos, como:

- la conexión económica y política del Estado chileno con América Latina;

- la oferta de turismo en Chile, en especial hacia los países con los cuales hay acuerdos de libre intercambio;

- Emitir series de TV chilena y cine chileno, en línea y en VOD. El cine chileno que ha sido exitoso en festivales internacionales, necesita una ventana televisiva internacional para convocar audiencias a su visionado en salas.

- Exhibir espacios de conexión con las colonias chilenas en el exterior.

\section{Señal generalista}

Esta es la señal actual de TVN en TV análoga abierta, la cual necesita acomodarse al nuevo escenario digital y segmentado. Hay programación televisiva que puede continuar en una señal digital generalista; algunos programas de acompañamiento a personas del hogar, con el cambio etario en Chile crecerá el aspecto de programación para la audiencia de tercera edad; la función de compañía de la TV ha sido redescubierta y apreciada; aquí aparecen géneros que asumen temas de la vida cotidiana. Otro tipo de programación donde TVN ya ha tenido éxito es avanzar hacia la constitución de un conjunto de festivales regionales de música popular (Olmué, Talca, Antofagasta); en colaboración con las estaciones regionales de TVN estos festivales acentúan el desarrollo cultural regional y constituyen un complemento al Festival Internacional de Viña del Mar.

Un tercer aporte segmentado de TVN generalista es apoyar a la industria cultural audiovisual que alimenta con ficción de telenovelas y series a la TV, y al cine de salas. Esta es una industria de creciente importancia en la economía nacional y en la exportación; requiere premiar a las obras que conquisten audiencia y generan distribución en multiplataforma.

Por otra parte, la TV no es solamente un medio exhibidor de obras (como pensaba el cineasta Jean-Luc Godard); los formatos ficcionales propios de la TV (como la telenovela y las series) generan un importante monto de honorarios a actores y a otras especializaciones artísticas; a fines de los ' 90 era posible calcular que la TV chilena en conjunto traspasaba a los artistas del área dramática televisiva entre 5-10 millones de 
dólares anuales; una parte de esta cantidad era invertida por los artistas para montar y experimentar obras de teatro en salas, el lugar propio de la exhibición del teatro.

La TV no solo es un medio exhibidor de obras sino sustentador económico de obras en otros medios; ello permite al artista que trabaja en TV invertir en sus propios intereses. Esta realidad hace posible construir un círculo virtuoso entre TV y Teatro, TV y Música, respetando cada uno sus espacios de creaciones. Potenciar y amplificar estos circuitos virtuosos puede ser importante para el desarrollo de las industrias creativas chilenas. Y esto se aloja en un canal generalista y algunos canales segmentados (infantiles, por ejemplo) como un servicio de mutuo soporte con la industria cultural.

\section{Financiamiento}

Hasta aquí se ha presentado una modernización de TVN hacia una empresa multicanal, con un servicio público segmentado en cinco señales: un fuerte servicio público informativo, desarrollo formativo de los niños, desarrollo regional, desarrollo de la industria creativa cultural y una señal internacional. Un proyecto de esta naturaleza y con sus contenidos segmentados no es sustentable únicamente con publicidad comercial. Se propone entonces, un esquema mixto, con aportes publicitarios y públicos (tal era el proyecto inicial del Presidente Aylwin, que el Congreso no aprobó en 1992). Se puede constatar una fuerte aspiración (¿campaña?) de las estaciones privadas para eliminar totalmente la publicidad en TVN.

La propuesta reciente de quitar toda publicidad como financiamiento de TVN y cobrar un impuesto a los canales en TV abierta para financiar TVN (según el modelo español) no tiene ningún estudio económico de respaldo. Ciertamente no es bien comentado por los canales privados chileno. Pero su aporte económico es muy dudoso ya que todos los canales, con excepción de Mega, generan pérdidas. Nunca se ha explorado la posibilidad de cobrar impuestos a la TV chilena de pago en beneficio de TVN; la TV de pago tiene una doble fuente de financiamiento: el cobro mensual del abono a la compañía distribuidora y la publicidad en pantalla.

La publicidad tiene dos elementos valiosos en la gestión de un canal de TV público: introduce control de costo/beneficio dificultando la hipertrofia y la corrupción; introduce también aprecio a la audiencia de los programas. Un canal generalista con creación ficcional en TVN puede tener publicidad comercial (menos riesgosa que en una señal de información). Incluso un canal segmentado hacia niños puede exhibir una cuota (pequeña seguramente) de publicidad genérica de alimentos, útiles para combatir la epidemia de la obesidad (frutas, vegetales, lácteos, y otros).

Los balances de TVN deben ser auditados externamente como dispone la ley de Reforma del 92, y los aportes del Estado deben ser controlados por la Contraloría General de la República; la gestión de TVN previa a la crisis fue innovadora y desincentivó la corrupción; muchos ejecutivos de TVN trabajan hoy en otros canales, prueba de su capacidad creativa y de gestión. Los canales regionales pueden tener fuentes económicas en los fondos generales de TVN, en publicidad local, y en fondos públicos regionales.

\section{Dirección Superior}

Aquí aparecen tres puntos interrelacionados por resolver.

a) La composición y tamaño del Directorio de TVN; b) La función del Ejecutivo y del Congreso; c) otras formas de participación social. 
Estos aspectos de dirección superior son tan complejos que no hay soluciones óptimas sino menos malas.

Lo más fácil de resolver es el tamaño del Directorio. Debe ser una dirección operativa y rápida en un ambiente industrial muy dinámico; un directorio no es una asamblea de opiniones. Un tamaño de 7-9 personas es indispensable. Deben compartir ciertos rasgos básicos acerca de la empresa que manejan tales como conocer la industria televisiva, compartir la necesidad del pluralismo informativo y las funciones públicas asignadas a la empresa, capacidad de gestión con un manejo financiero serio y responsable, compartir la necesidad de audiencia (una TV Pública sin público es un contrasentido) ${ }^{15}$. La actual crisis de TVN muestra que estos rasgos son más fácilmente aceptados de modo verbal que puestos en práctica, responsabilizándose ante el fracaso.

¿Quién elige a estos directores y qué competencias deberían tener los directores? El actual mecanismo legal chileno está inspirado en la BBC. El Presidente de la República designa libremente al Presidente del Directorio de TVN; y el Presidente de la República negocia con el Senado los restantes directores en lista cerrada para mantener la pluralidad (con una aprobación calificada, superior a la mayoría); designación escalonada en el tiempo, que no debe coincidir con el comienzo de cada Presidencia de la República. Aquí aparece que la preocupación central de la BBC ( $y$ de TVN) ha sido crear un mecanismo que garantice el pluralismo en el Directorio, su incidencia en la calidad de las designaciones internas, y en la calidad plural de la información política; pero esa garantía de pluralismo no garantiza la capacidad para la gestión televisiva de una industria compleja y dinámica, de los directores negociados entre el Presidente y el Senado; tampoco del Presidente del Directorio. Si los directores entre sí y con el Presidente del Directorio tienen discrepancias irreconciliables acerca de la misión y gestión de TVN (como ha sucedido varias veces en esa estación) el canal se paraliza y entra en crisis. La crisis actual en gran parte se originó en diferencias paralizantes entre el Presidente del Directorio y el Director Ejecutivo de la época (inicio de los 2000); el resultado inmediato fue el desmantelamiento del área dramática de TVN capturada por Megavisión.

Muchos políticos no tienen claridad acerca de la gestión de una empresa televisiva, que debe tener una audiencia significativa para tener influencia social. UNESCO por años ha hecho esfuerzos por introducir buenas prácticas de gestión en la TV pública latinoamericana, con pobres resultados ante la indiferencia de los gobiernos (Fuenzalida, 2006, 117-144; Becerra y Waisbord, 2015).

Hay estatutos jurídicos que han diseñado otro cuerpo social plural y amplio, en lugar del Senado o el Congreso, el cual que elige al pequeño Directorio profesional para la gestión operacional de un canal público. En Alemania la primera cadena de TV pública (ARD) tiene una organización escalonada en niveles. Un Consejo de TV (Radiodifusión) amplio de alrededor 40-60 integrantes (políticos nominados por el Parlamento y el Gobierno, y representantes de sociedad civil nominados por Iglesias, agrupaciones de educadores, universidades, y otras organizaciones); el Consejo de TV elige al Consejo de administración

15 Los fracasados canales latinoamericanos de propaganda gubernamental y sin audiencia han inventado ingeniosas explicaciones para su déficit de audiencia, las cuales se repiten en diversas reuniones internacionales. La pequeña audiencia sería un "rating de alta calidad"; serían pequeños pero influyentes sectores "de alto nivel socio-cultural", o de "alta conciencia política". Afirmaciones verbales para las cuales no se exhibe ninguna comprobación. 
de unos 9 miembros; este Consejo pequeño elige al Intendente o Director Ejecutivo del canal con aprobación del Consejo de TV; los miembros (ad honorem) de los Consejos y el ejecutivo superior tiene tiempos establecidos de duración en sus cargos, pero hay mecanismos para destitución con altas mayorías. Este esquema tiene variaciones según los estados regionales alemanes. Este esquema ha influido también en la estructura de dirección del canal TV Cultura de Sao Paulo, canal privado y con aporte económico público del Estado de Sao Paulo. El sistema alemán también recibe críticas en su país hacia las personas elegidas como representantes, con intereses desajustados de las audiencias, y por negociaciones políticas para acuerdos en designaciones internas para adquirir posibles cuotas de influencia.

Hay dos informaciones que podrían ayudar a elegir un mejor directorio para TVN: recoger la experiencia de los ex Presidentes del Directorio de TVN junto a los ex Directores ejecutivos, y consultar la experiencia de la Alta Dirección Pública en Chile, que ha mejorado la selección de candidatos a la dirección superior de servicios públicos. Una primera selección de candidatos al Directorio de TVN por la Alta Dirección Pública podría ser propuesta en ternas para la decisión del Congreso y del Presidente de la República.

Un mecanismo adecuado, se puede esquematizar así: el Senado como nivel plural amplio,

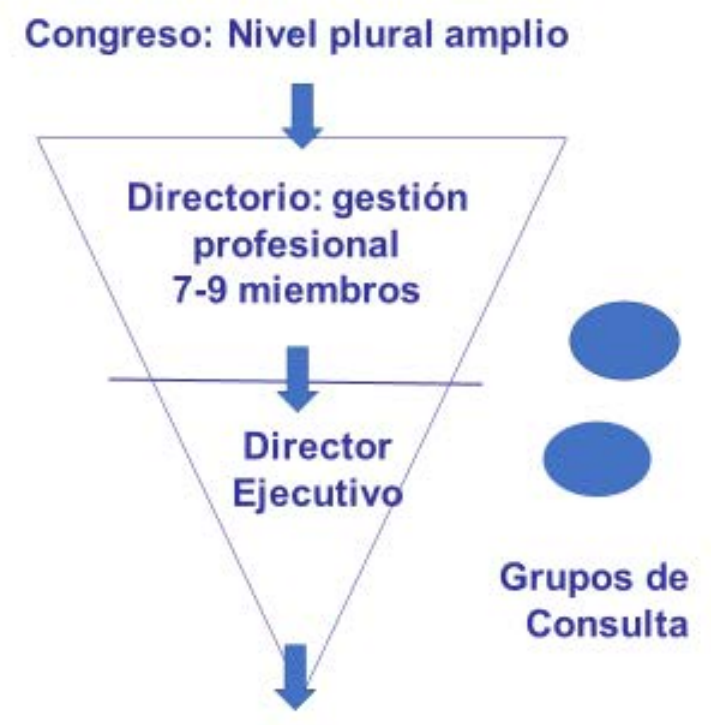

\section{Administración Profesional}

al cual el Presidente propone las ternas elaboradas por la Alta Dirección

Pública. El Senado elige de entre las ternas las personas que tengan las destrezas apropiadas. Ellos eligen al Director Ejecutivo, quien propone al Directorio el cuerpo directivo superior, y lo evalúa.

Los grupos de consulta social "ad honorem" deben establecerse alrededor de la Directorio para las señales nacionales, la señal internacional y para las regionales; ellos también se inspiran en prácticas de la BBC: reunir una vez al año a diferentes representantes de algunas áreas sociales sensibles (educación, información, seguridad, salud, por ejemplo). 
Entregando previamente informes de programación televisiva y conceptos acerca de los temas e intentando alcanzar recomendaciones operativas en programación. Estas deliberaciones son propuestas, que la administración puede tomar en cuenta para tomar decisiones.

Otra práctica de la BBC que puede ser muy útil a TVN es la revisión cada diez años acerca y del Estado de la empresa, sus logros y deficiencias, y su Proyecto televisivo para la década venidera. Tal informe se presenta a la Cámara de los Comunes en Gran Bretaña y aprobado constituye la Royal Chart para el próximo decenio de la estación. Es más útil que un informe anual, como se ha definido en Chile; esa revisión y planificación en el mediano plazo ha sido importante en el éxito mantenido de la BBC como un servicio público televisivo apreciado y confiable, con audiencia, fortaleza industrial y presencia global.

\section{En sintesis}

Este texto plantea que TVN necesita una modernización inevitable planteada por las nuevas tecnologías de emisión/recepción y por los nuevos conocimientos acerca de la recepción por las audiencias. Las audiencias tienen más capacidades activas ante los mensajes de comunicación que las planteadas hace siglo y medio atrás tanto por el conductismo de USA como el conductismo pavloviano. La información para persuadir electores a votar por representantes ha perdido relevancia práctica - es cada vez más difícil que los ciudadanos vayan a votar. Se ha ensayado formas de publicidad y propaganda electoral con resultados poco duraderos. Se está terminando el enfoque de la información como una mirada propagandística (que persiste en América Latina en los inútiles canales de propaganda gubernamental). El cambio es hacia la comunicación entendida como más amplia discusión y deliberación social acerca de las políticas para resolver las necesidades de la ciudadanía. Y con participación de las audiencias ciudadanas. La ciudadanía está más empoderada por su mayor nivel socio-educativo y desconfía de la representación de los políticos. La crítica en muchas partes del mundo es que la profesionalización de los políticos más bien los ha constituido en una clase oligárquica, bien rentada, e interesada más bien en mantener sus privilegios (Marschall, 2002).

La TV pública necesita dejar en el pasado las formas propagandísticas de información política. Son audiencias están empoderadas por la recepción intertextual y multimodal desde diversas fuentes ubicuas (every time every where). La segmentación de contenidos en las opciones de las audiencias lleva a la segmentación en los canales de emisión. No son audiencias pasivas y persuasibles por cualquier programa. Las dictaduras, los engaños y la corrupción han generado audiencias desconfiadas que hoy disponen de medios digitales muy rápidos de contrastación informativa. TVN tampoco puede ser planteada como un canal lineal y generalista: la tecnología evolucionó y también las audiencias. Por ello aquí se proponen varios canales segmentados y multiplataformas para las audiencias. Se ha hecho una exposición más extensa acerca de algunos canales (como información y niños) por los grandes cambios conceptuales que han ocurrido. Del periodismo de propaganda política se ha pasado al concepto de periodismo informativo para la deliberación de la ciudadanía y con participación de la ciudadanía; por ello se ha hecho énfasis en la necesidad de ampliar los géneros y formatos de información; no es una especulación académica sino una realidad actual para mejorar la relación de la ciudadanía con la política democrática. En la TV infantil desde las emisiones vinculadas a la escuela se ha evolucionado hacia los contenidos de TV socioemocional. TVN necesita urgentemente renovarse en contenidos valiosos para las audiencias actuales; y requiere también una renovación en gestión y un financiamiento público adecuado como un servicio público a la ciudadanía. Esta renovación requiere ser formulada primeramente por el Directorio de TVN, como un "petit comité" 
- Valerio Fuenzalida

que se reúne periódicamente, y con continuidad de revisión del avance; es ilusorio imaginar que una reforma de esta complejidad brotará de un congreso masivo. Al revés: las propuestas elaboradas y meditadas, entonces pueden ser presentadas para ser discutidas en grupos amplios. Pienso que es la tarea más importante para el Directorio de TVN. 


\section{Referencias bibliográficas}

ÁVILA C. 2017. Comunicación de gobierno en el populismo latinoamericano: El caso de Rafael Correa, Ecuador (tesis de doctorado). Pontificia Universidad Católica de Chile, Santiago, Chile. https:// repositorio uc.cl/handle/1534/21604

BECERRA M. y Waisbord S. 2015. Principios y "buenas prácticas" para los medios públicos en América Latina. Cuadernos de Discusión de Comunicación e Información 3. París. UNESCO.

FUENZALIDA V. 2000. La Televisión Pública en América Latina. Reforma o Privatización. Santiago: Fondo de Cultura Económica.

FUENZALIDA V. 2002. The Reform of National Television in Chile. En: Latin Politics, Global Media. Fox E. \& Waisbord S. (eds.). Austin: University of Texas Press.

FUENZALIDA V. 2005. Expectativas educativas de las audiencias televisivas. Bogotá: Ed. Norma.

FUENZALIDA V. 2006. La reforma de TVN en Chile: logros y problemas. Indrajit Banerjee y Kaling Seneviratne (eds.). En: Radiotelevisión de Servicio Público: Un Manual de Mejores Prácticas. San José de Costa Rica: Oficina de la UNESCO para América Central.

FUENZALIDA V. 2007. Reconceptualización de la Entretención ficcional televisiva. Fronteiras. IX (1) 45-54. Porto Alegre: Universidad de Unisinos.

FUENZALIDA V. 2008. El Docudrama televisivo. MATRIZes. Ano $2 N^{0}$ 1, p. 159-171. São Paulo: Programa de Pós-Graduação em Ciências da Comunicação da USP.

FUENZALIDA V. 2016. La Nueva Televisión Infantil. Santiago: Fondo de Cultura Económica.

HALLIN D.C. \& Mancini P. 2004. Comparing Media Systems. Cambridge University Press.

JAUSS H.R. 1982. Interaction Patterns of Identification with the Hero. En: Aesthetic Experience and Literary Hermeneutics. Minneapolis: University of Minnesota Press.

MARSCHALL S. 2002. El parlamento en la sociedad de medios - interacción entre el debate parlamentario y mediático. En: Priess F. (ed.). Relación entre Política y Medios. Propuestas alemanas en una perspectiva comparada. Buenos Aires: KAS.

MULGAN Geoff. 1990. Television's Holy Grail: Seven Types of Quality. En: The Question of Quality. Mulgan Geoff (ed.). BFI. London

SOUKUP P. 2014. Political Communication. Communication Research Trends, vol. $33 \mathrm{~N}^{\circ} 2$. Santa Clara: Santa Clara University.

SUNKEL G. \& Geoffroy E. 2001. Concentración económica de los medios de comunicación. Santiago: LOM Ediciones. 
- Valerio Fuenzalida

URIBE R. 2007. Redefiniendo y Reivindicando la presencia de la Emocionalidad en la Comunicación Social. La Función Política de la Televisión. Tendencias, contenidos y desafíos en el Chile de hoy. Secretaría de Comunicaciones. Santiago: Palacio La Moneda.

VALIDA CHILE. Boletines de Circulación y Lectura. Valida-Chile.cl

WAISBORD S. 2018, Why Populism is Troubling for Democratic Communication. Communication Culture \& Critique 11 (2018) 21-34. Downloaded from https://academic.oup.com/ccc/article-abstract/11/1/21/4953072 by guest; on 27 March 2018. 